\title{
ACQUIRED VULVAL LYMPHANGIECTASIA CLOSELY MIMICKING GENITAL WARTS
}

Antionetta Ashwini' ${ }^{1}$ Krishnakanth ${ }^{2}$, Mahalakshmi V ${ }^{3}$, Anandan S4, R. Sudha ${ }^{5}$

\section{HOW TO CITE THIS ARTICLE:}

Antionetta Ashwini, Krishnakanth, Mahalakshmi V, Anandan S, R. Sudha. "Acquired Vulval Lymphangiectasia Closely Mimicking Genital Warts". Journal of Evolution of Medical and Dental Sciences 2014; Vol. 3, Issue 54, October 20; Page: 12504-12507, DOI: 10.14260/jemds/2014/3655

ABSTRACT: A 41 years female was referred to our OPD from a primary health care centre with a diagnosis of condyloma accuminata of the vulva, a known case of carcinoma cervix and completed 25 cycles of radiotherapy.

KEYWORDS: Lymphangiectasia, lymphangioma circumscriptum, radiotherapy.

INTRODUCTION: Acquired lymphangiectasia of the genitals is a common complication of genitourinary malignancies. The translucent vesicles typical of this condition may undergo secondary keratotic changes which may present as verrucous papules mimicking genital warts.

CASE REPORT: A 41 yrs female came with complaints of asymptomatic verrucous lesions over the entire right vulval area, extending to the left side, for $1 \mathrm{yr}$ duration. History of watery discharge from the lesion was present. Patient is a known case of carcinoma cervix - stage 2B and patient had completed 25 cycles of radiotherapy 2 yrs ago, followed by Werthiems hysterectomy.

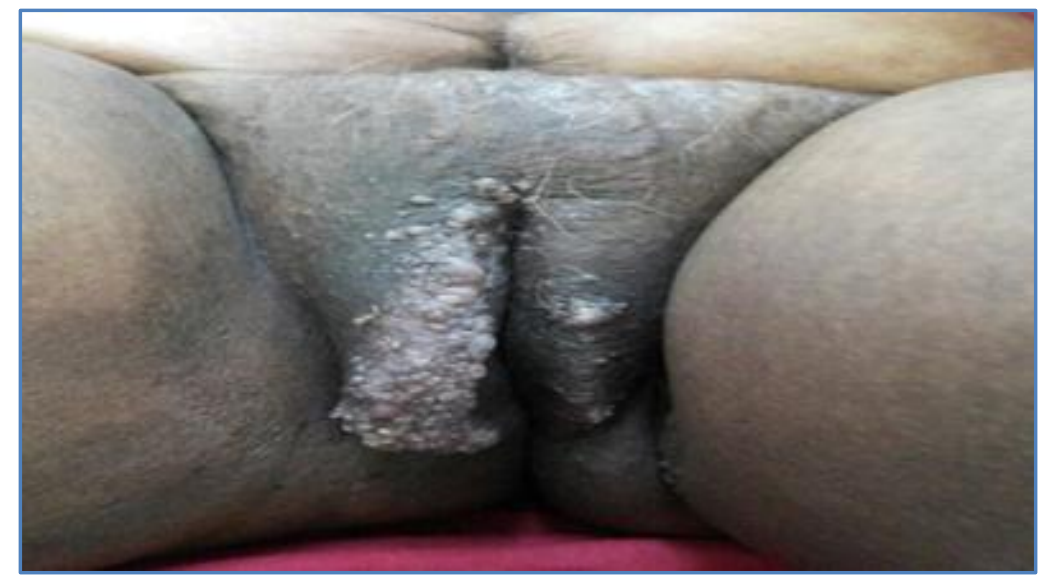

Figure 1: Lymphangioma circumscriptum of the vulva

On clinical examination, multiple vesicles and verrucous papules conglomerating to form a large plaque involving the entire outer lip of the vulva on the right side. Few non-friable verrucous papules over the left vulva were present. The lesions were firm in consistency and immobile with no regional lymphadenopathy.

On investigations, All blood and radiological investigations were within normal limits.

Vulval biopsy showed - Multiple dilated lymphatic vessels lined by thin wall comprising of endothelial cells within the papillary dermis suggestive of lymphangiectasia. 


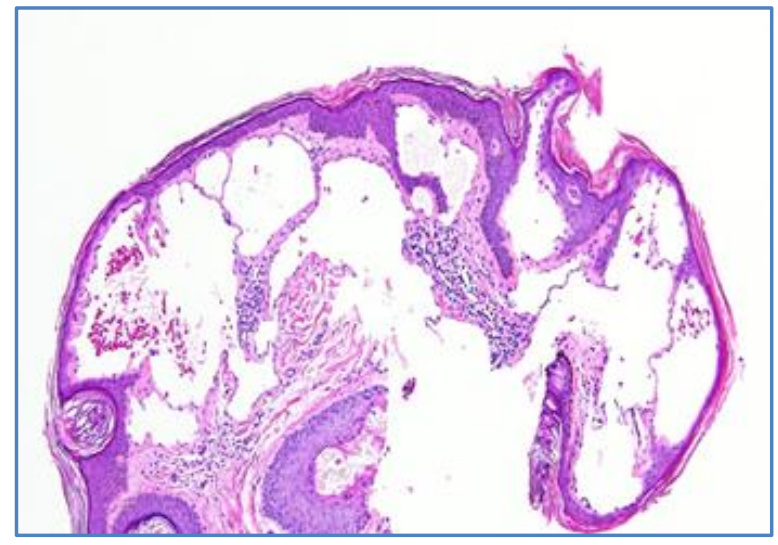

Figure 2: Histopathology of

lymphangioma circumscriptum

Treatment: Wide excision of the lesion (VULVECTOMY) was done.

DISCUSSION: A lymphangioma also known as lymphatic malformation, is a congenital proliferation of lymphatic vessels, which are of three types lymphangioma - circumscriptum, cavernous, and cystic.(2)

Lymphangioma circumscriptum (LC) is either primary (usually present at birth or develops in early childhood) or secondary (induced by impairment of lymph flow). Secondary lymphangioma is also termed acquired lymphangioma and lymphangiectasis.

The commonest form of cutaneous lymphangioma is lymphangioma circumscriptum, which arises in infancy but may occur at any age. It is characterized by small clusters of vesicles; measuring about 2-4 mm; contain clear lymph fluid.(11) The typical history involves a small number of vesicles on the skin at birth or shortly after. In subsequent years, they tend to increase in number, and the area of skin involved continues to expand.

Vesicles or other skin abnormalities may not be noticed until several years after birth. Usually asymptomatic, but, occasionally, patients have spontaneous episodes of minor bleeding and copious drainage of clear fluid from ruptured vesicles. Although it may appear localized to the dermis, it can frequently extends deeply and laterally. The lesions can have a warty appearance; as a result, they are often confused with warts as in our patient. The sites of predilection are the proximal extremities, trunk, axilla, and oral cavity, especially the tongue. Involvement in other areas, such as the scrotum, is not uncommon. ${ }^{(13,14)}$

Vulvar LC can be asymptomatic,(6) pruritic,(12) burning(5) or painful.(12) In our patient, the lesion occurred following carcinoma of the cervix post therapy. Although various modalities of treatment have been suggested, surgical excision is the treatment of choice for the lesions confined to superficial dermis with highest success rate.(3)

Other treatment modalities include X-rays,(10) radiotherapy,(4) cryotherapy, sclerotherapy,(1) cautery, argon laser,(9) $\mathrm{CO}_{2}$ laser(7) and pulse dye laser.(8) Our patient was treated with vulvectomy with good improvement. 


\section{REFERENCES:}

1. Al Ghamdi and Mubki, 2011 May K.M. AlGhamdi, T.F. Mubki Treatment of lymphangioma circumscriptum with sclerotherapy: an ignored effective remedy J. Cosmet. Dermatol. 10 (2) (2011), pp. 156-158.

2. Brown and Stenchever, 1989 May J.V. Brown, M.A. Stenchever Cavernous lymphangioma of the vulva Obstet. Gynecol., 73 (5 Pt 2) (1989), pp. 877-879.

3. Browse et al., 1986 N. L. Browse, I. Whimster, G. Stewart, C.W. Helm, J. J. Wood Surgical management of lymphangioma circumscriptum Br. J. Surg., 73 (1986), pp. 585-588.

4. Denton et al., 1996 A.S. Denton, R. Baker-Hines, M.F. Spittle Radiotherapy is a useful treatment for lymphangioma circumscriptum: a report of two patients Clin. Oncol. (R. Coll. Radiol.), 8 (1996),

5. Fisher and Orkin, 1970 I. Fisher, M. Orkin Acquired lymphangioma (lymphangiectasis). Report of a case .Arch. Dermatol., 101 (1970), pp. 230-234.

6. Handfield-Jones et al., 1989 S.E. Handfield-Jones, W.J. Prendiville, S. Norman Vulval lymphangiectasia Genitourin. Med., 65 (1989), pp. 335-337.

7. Huilgol et al., 2002 S.C. Huilgol, S. Neill, R.J. Barlow $\mathrm{CO}_{2}$ laser therapy of vulval lymphangiectasia and lymphangioma circumscriptum Dermatol. Surg., 28 (2002), pp. 575-577.

8. Lai et al., 2001 C.H. Lai, S.G. Hanson, S.B. Mallory Lymphangioma circumscriptum treated with pulsed dye laser Pediatr. Dermatol., 18 (2001), p. 50910.

9. Landthaler et al., 1982 M. Landthaler, D. Haina, W. Waidelich, O. Braun-Falco Treatment of circumscribed lymphangiomas with the argon laser Hautarzt, 33 (1982), pp. 266-270.

10. O'Cathail et al., 1985 S. O'Cathail, A.Y. Rostom, M.L. Johnson Successful control of lymphangioma circumscriptum by superficial X-rays Br. J. Dermatol., 113 (1985), pp. 611-615.

11. Patel et al., 2009 G.A. Patel, R.D. Siperstein, G. Ragi, R.A. Schwartz Zosteriform lymphangioma circumscriptum Acta Dermatovenerol. Alp. Panonica Adriat., 18 (4) (2009), pp. 179-182.

12. Sood et al., 1991 M. Sood, A.K. Mandal, K. Ganesh Lymphangioma circumscriptum of the vulva J. Indian Med. Assoc., 89 (1991), pp. 262-263.

13. Swanson, 2006 D.L. Swanson Genital lymphangioma with recurrent cellulitis in men Int. J. Dermatol., 45 (2006), p. 800.

14. Vlastos and et al., 2003.

15. A.-T. Vlastos, et al. Lymphangioma circumscriptum of the vulva: a review of the literature Obstet. Gynecol., 101 (2003), p. 946. 


\section{AUTHORS:}

1. Antionetta Ashwini

2. Krishnakanth

3. Mahalakshmi V.

4. Anandan S.

5. R. Sudha

\section{PARTICULARS OF CONTRIBUTORS:}

1. Resident, Department of Dermatology, Sri Ramachandra University.

2. Assistant Professor, Department of Dermatology, Sri Ramachandra University.

3. Professor, Department of Dermatology, Sri Ramachandra University.

4. Professor, Department of Dermatology, Sri Ramachandra University.
5. Professor, Department of Dermatology, Sri Ramachandra University.

\section{NAME ADDRESS EMAIL ID OF THE} CORRESPONDING AUTHOR:

Dr. Antionetta Ashwini, No. 5, Neelakantha Metha Street, T. Nagar, Chennai-17.

Email: drantionettaashwini@gmail.com

Date of Submission: 23/09/2014. Date of Peer Review: 24/09/2014. Date of Acceptance: 15/10/2014. Date of Publishing: 20/10/2014. 